\title{
A MEDIAÇÃO E A CONCILIAÇÃO NO NOVO CÓDIGO DE PROCESSO CIVIL: MAXIMIZAÇÃO DE EFICIÊNCIA NA JUSTIÇA BRASILEIRA
}

\author{
Fabiana Junqueira Tamaoki Neves ${ }^{1}$ \\ Ewerton Ricardo Messias ${ }^{2}$
}

\begin{abstract}
Resumo
O presente artigo visa analisar o desenvolvimento de novas metodologias e tendências do Processo Civil com relação aos meios alternativos de solução de conflitos e as bases em que se fundam, sob a ótica da autocomposição. Nesse intuito, são investigadas as definições e as diferenças entre estes dois institutos, uma possível evolução legislativa acerca da mediação e da conciliação, a natureza jurídica dos acordos obtidos no âmbito destes institutos e uma possível maximização de eficiência na Justiça brasileira propiciada por eles. Para a obtenção dos resultados almejados pela pesquisa, o método de abordagem seguido foi o empírico-dialético, utilizando-se das pesquisas bibliográfica e legislativa, tendo como sistema de referência uma combinação do Constructivismo Lógico-Semântico de Paulo de Barros carvalho e do Law and Economics de Richard A. Posner. Em conclusão, aponta-se para uma ampliação da celeridade processual, a qual possibilita uma maximização de eficiência na Justiça brasileira, por meio de uma resolução alternativa de conflitos apta a garantir a fruição plena do direito de acesso à justiça, baseada na fruição tempestiva, pelos cidadãos, dos direitos que lhe foram tolhidos ou negados ilegalmente.
\end{abstract}

Palavras-chave: Pós-modernidade. Meios alternativos de solução de conflitos. Maximização de eficiência. Acesso à Justiça. Dignidade da pessoa humana.

\section{INTRODUÇÃO}

A evolução do período moderno para o período pós-moderno foi caracterizada por fortes alterações nas relações jurídicas e sociais

$\mathrm{Na}$ pós-modernidade, no que se refere à área jurídica, ocorreram alterações caracterizadas pela socialização e pela constitucionalização do Direito, assumindo, a principiologia constitucional, o lugar antes

\footnotetext{
${ }^{1}$ Professora no Programa de Pós-Graduação Stricto Sensuda Universidade de Marília - UNIMAR. Professora nos cursos de Graduação em Direito e Serviço Social do Centro Universitário Toledo de Presidente Prudente. Professora no curso de Graduação em Direito da Universidade de Marília - UNIMAR. Doutora em Sistema Constitucional de Garantia de Direitos pela Instituição de Ensino de Bauru (ITE).E-mail: fatamaoki@gmail.com.

${ }^{2}$ Professor nos cursos de Graduação em Direito e Administração da Universidade de Marília - UNIMAR. Professor no Curso de Especialização em Policiamento Ambiental no Comando de Policiamento Ambiental da Polícia Militar do Estado de São Paulo. Doutorando em Direito pela Universidade de Marília - UNIMAR.E-mail: ewerton_messias@hotmail.com.
} 
ocupado pelo positivismo jurídico, representado pelas codificações oitocentistas.

$\mathrm{Na}$ área social ocorrem alterações caracterizadas pela fluidificação dos vínculos entre as pessoas e entre estas e os objetos.

O vínculo forte e duradouro, qualificado por aspectos como a durabilidade, a profundidade e a solidez, que caracterizavam a relação entre as pessoas e entre estas e os objetos na modernidade, cede espaço, na pósmodernidade, a um vínculo não duradouro, qualificado por aspectos que tornam frágeis as relações sociais, como a efemeridade, a superficialidade e a fluidez.

A crise nas relações interpessoais, vivenciada na pós-modernidade, resulta de uma crise de valores, caracterizada pela ausência de valores como respeito, empatia, honradez e coerência, dentre outros, nas relações entre as pessoas.

No âmbito da sociedade brasileira, esta nova realidade das relações entre as pessoas, tem aumentado o número de conflitos, de forma a gerar, ano após ano, um aumento de demandas distribuídas junto à Justiça brasileira.

Diante desta nova realidade, pergunta-se: Seriam a mediação e a conciliação aptas a propiciar uma maior celeridade na Justiça brasileira? Sendo aptas a propiciar uma maior celeridade processual, revelar-se-iam a mediação e a conciliação com meios alternativos de resolução de conflitos aptos a propiciar uma maximização de eficiência na Justiça brasileira?

A justificativa para a pesquisa do tema em tela é a necessidade de aprofundamento dos estudos acerca das bases em que se fundam tais meios alternativos de resolução de conflitos, sob a ótica da autocomposição, como meio para uma maximização de eficiência na Justiça brasileira, tendo por esteio a garantia da mais ampla fruição do direito fundamental de acesso à Justiça, como forma de efetivação do princípio da dignidade da pessoa humana e do objetivo de construção de uma sociedade justa e solidária, previstos na Constituição Federal de 1.988.

Quanto ao objetivo a ser alcançado, trata-se de uma tentativa de clarificar as definições e as diferenças entre a mediação e a conciliação; uma possível evolução legislativa acerca de tais institutos; a natureza jurídica dos acordos obtidos no âmbito deles; e uma possível maximização de eficiência na Justiça brasileira propiciada por eles.

A despeito da suma importância da matéria abordada, o tema ainda carece de pesquisa aprofundada sob o prisma que ora se pretende focalizar, lacuna esta que, ao ser preenchida, certamente trará auxílio doutrinário ao intérprete e ao aplicador do Direito, contribuindo para que as normas jurídicas constitucionais e infraconstitucionais, relacionadas a tal temática, possam ser aplicadas de forma mais eficaz.

Para a obtenção dos resultados almejados pela pesquisa, o método de abordagem a ser seguido será o 
empírico-dialético ${ }^{3}$, utilizando-se das pesquisas bibliográfica, legislativa e jurisprudencial, tendo como sistema de referência uma combinação do Constructivismo Lógico-Semântico ${ }^{4}$ de Paulo de Barros Carvalho e do Law and Economics de Richard A. Posner ${ }^{5}$.

\section{A CONCILIAÇÃO E A MEDIAÇÃO COMO NORMAS FUNDAMENTAIS DO PROCESSO CIVIL}

Primeiramente, antes do estudo mais aprofundado dos institutos da conciliação e da mediação, faz-se necessária compreensão acerca da definição ${ }^{6}$ de tais institutos.

A conciliação e a mediação são institutos que, atualmente, estão em evidência, pois, sua finalidade é

\footnotetext{
${ }^{3}$ Para Lourival Vilanova, "os objetos culturais, entre os quais se aloja o direito, são todos aqueles que estão na experiência, tendo existência real, contudo sempre valiosos, positiva ou negativamente. O ato gnosiológico próprio é a "compreensão" e o método da correspondente ciência é o "empírico-dialético"”. VILANOVA, Lourival. Fundamentos do Estado de Direito. In: Escritos Jurídicos e Filosóficos, vol. I. São Paulo: IBET/Axis-Mundi, 2008.p.82.

${ }^{4} \mathrm{O}$ constructivismo lógico-semântico é um instrumento de trabalho, modelo para ajustar a precisão da forma à pureza e à nitidez do pensamento; meio e processo para a construção rigorosa do discurso, no que atende, em certa medida, a um dos requisitos do saber científico tradicional. O modelo constructivista se propõe amarrar os termos da linguagem, consoante esquemas lógicos que deem firmeza à mensagem, pelo cuidado especial com o arranjo sintático da frase, sem deixar de preocupar-se com o plano do conteúdo, selecionando as significações mais adequadas à fidelidade da enunciação. CARVALHO, Paulo de Barros. Constructivismo lógico-semântico. Disponível em https://enciclopediajuridica.pucsp.br/verbete/101/edicao-1/constructivismologico-semantico. Acesso em 14 jun. 2017.

${ }^{5}$ A análise econômica do direito, como atualmente existe não só nos Estados Unidos mas também na Europa, que tem a sua própria associação de direito e economia florescente, tem aspectos positivos (que é descritivo) e aspectos normativos. Ela tenta explicar e prever o comportamento dos participantes e nas pessoas reguladas pela lei. Ela também tenta melhorar a aplicação da lei por chamar a atenção para aspectos em que as leis existentes ou propostas têm consequências não intencionais ou indesejáveis, quer sobre a eficiência econômica ou a distribuição do rendimento e da riqueza, ou outros valores. Ela não é uma simples empresa de marfim, pelo menos nos Estados Unidos, onde o movimento de direito e economia é entendido por ter influenciado a reforma jurídica num certo número de áreas importantes. [...] Análise econômica do direito é geralmente considerada o desenvolvimento mais significativo no pensamento jurídico nos Estados Unidos desde o desaparecimento do realismo jurídico há meio século (Texto em inglês no original). POSNER, Richard A. Values and consequences: As an introduction to economic analysis of law. University of Chicago Law School. John M. Olin law \& Economics Working Paper n. 53. 2D Series. Chicago: 1998, p.2. Disponível em http://m.law.uchicago.edu/files/files/53.Posner.Values_0.pdf. Acesso em 29 jul. 2017.

${ }^{6}$ Conceito é a classe, a palavra, enquanto definição é a tentativa de enunciar-se de uma maneira precisa o uso comum das palavras e seus limites, ou seja, é a tentativa de explicar o conceito. Definição é algo enunciável, que se pode dizer de forma geral e em poucas palavras. No mesmo sentido, Jonathan Barros Vita identifica o conceito "[...] como a classe, a palavra, enquanto a definição contém os critérios para ingresso nesta classe (definição conotativa) ou os elementos componentes desta classe (definição denotativa)”. VITA, Jonathan Barros. Valoração aduaneira e preços de transferência: pontos de conexão e distinções sistêmico-aplicativas. 2010, 927f, p.32. Tese de Doutorado - Pontifícia Universidade Católica. São Paulo. Disponível em: https://sapientia.pucsp.br/bitstream/handle/5458/1/Jonathan\%20Barros\%20Vita.pdf. Acesso em: 06 abr 2017. As formas de definição são conotativa e denotativa. A definição conotativa revela-se na delimitação do uso da palavra, de forma a apontar, por meio de outros vocábulos, as características comuns que levam a nominar certos objetos por um determinado nome, de forma que, mesmo não enumerando tais objetos há possibilidade de identificá-los. A definição denotativa revela-se na enumeração dos objetos nomeados por determinado termo, de forma a permitir a identificação de seu conceito. Segundo Aurora Tomazini Carvalho "a classe é o âmbito de aplicação de um conceito, sua conotação é a totalidade dos requisitos que delimitam este conceito e sua denotação são todos os objetos que cabem no âmbito do conceito”. CARVALHO, Aurora Tomazini de. Teoria Geral Do Direito: O Constructivismo Lógico-Semântico. Tese. 30 ago. 13. 623 f. Dissertação de Mestrado - Pontifícia Universidade Católica. São
} 
tornar o processo judicial mais célere e, por vezes, evitar a instauração do mesmo, gerando, com isso, o tão almejado desafogamento do Poder Judiciário.

Ambos são meios alternativos de resolução de conflitos, que, por intermédio de um terceiro capacitado (conciliador/mediador), ajudam as partes, com os seus métodos e técnicas próprios, a chegarem a um consenso que seja benéfico a elas.

Todavia, os pontos nevrálgicos que os diferem, para a adoção deste ou daquele instrumento alternativo de resolução de conflitos, são a natureza do conflito e a maneira da condução pelo terceiro imparcial da audiência para a efetivação do acordo.

Conotativamente, a mediação pode ser definida como o meio alternativo para resolução de conflitos, por meio do qual o mediador incentiva as partes litigantes a colocarem fim a um litígio para que não haja a necessidade de judicialização da demanda, aproveitando-se de uma eventual relação de proximidade pré-existente entre as partes litigantes, cabendo ao mediador apenas conduzir o processo de facilitação da comunicação para a resolução consensual do litígio. Neste sentido, Cassio Scarpinella Bueno define a mediação como sendo "uma forma alternativa de solução de conflitos em que um 'mediador' estimulará os envolvidos a colocarem fim a um litígio existente ou potencial" (BUENO, 2011, p.47). Na mesma linha, Fredie Didier Júnior afirma que a mediação é mais indicada aos casos em que já existe proximidade das partes, relação que pode ser anterior ou permanente, pois cabe ao mediador facilitar a comunicação (DIDIERJÚNIOR, 2013, p.219).

Também conotativamente, a conciliação pode ser definida como o meio alternativo para resolução de conflito, por meio do qual o conciliador incentiva o fim de um litígio, iniciado em uma situação casual, na qual as partes não se conheciam anteriormente, visando a não judicialização da demanda, cabendo ao mediador apenas conduzir o processo de facilitação da comunicação para a resolução consensual do litígio. A conciliação revela-se como um meio alternativo de resolução de conflitos eficaz para os casos em que haja possibilidade da renúncia, submissão ou transação, muito comum, por exemplo, em relações obrigacionais de prestadores de serviço (SANTOS, 2004, p.18). Neste sentido, a conciliação pode ser entendida como:

[...] a técnica não adversarial mais adequada à resolução de conflitos objetivos, como os que surgem em decorrência de acidentes de trânsito, por exemplo. As partes não se conheciam anteriormente e o único vínculo existente entre elas é a necessidade de reparação dos danos causados. Trata-se de relacionamento meramente circunstancial. (GRINOVER, WATANABE E LAGRASTA NETO, 2008, pág. 54)

A conciliação é o meio alternativo de resolução de conflitos mais indicado para solucionar conflitos de consumo e outras relações casuais, nas quais não há interesse entre as partes de se manter um relacionamento, mas, sim, equacionar interesses materiais (VASCONCELOS, 2008, p.38).

Paulo. 30 ago. 2009, p.296. Disponível em: http://www.dominiopublico.gov.br/download/teste/arqs/cp098895.pdf. Acesso em: 29 mar. 2017. 
Na verdade a mediação distingue-se da conciliação em virtude da diferença da metodologia aplicada na resolução do conflito. Assim:

A mediação assemelha-se à conciliação: os interessados utilizam a intermediação de um terceiro, particular, para chegarem à pacificação de seu conflito. Distingue-se dela somente porque a conciliação busca sobretudo o acordo entre as partes, enquanto a mediação objetiva trabalhar o conflito, surgindo o acordo como mera consequência. Trata-se mais de uma diferença de método, mas o resultado acaba sendo o mesmo. (DINAMARCO, 2007, p.34)

No entanto, o que diferencia tais institutos sob a ótica da Lei no 13.105/2015 - NCPC?

Interpretando este macrossistema de forma sistemática ${ }^{7}$, verifica-se que o legislador infraconstitucional não se preocupou em definir estes meios alternativos de resolução de conflitos, no entanto, os trouxe inseridos em diversos capítulos dos seus livros, como maneira de fomentar a União, aos Estados, ao Distrito Federal e aos Municípios, logicamente, através dos seus entes, à solução consensual dos conflitos, seja endoprocessualmente ${ }^{8}$ ou extrajudicialmente?

Todavia, no Art. 165, \$\$ 2 e $3^{\circ}$ do NCPC, há um balizador objetivo hábil a indicar se em determinado caso concreto a atuação dar-se-á por meio da atuação de um conciliador ou de um mediador, qual seja, "a existência ou não de vínculo anterior entre as partes”(BRASIL, 2015).

Portanto, se o conflito apresentado for oriundo de um vínculo anterior entre as partes, isto é, de um laço que os une de amizade, de vizinhança, de sangue, de afeto, por exemplo, a norma jurídica ${ }^{10}$ indica que o meio

\footnotetext{
${ }^{7} \mathrm{O}$ método sistemático conduz o intérprete do direito a uma visão plena do direito positivo, ao permitir-lhe uma compreensão do direito enquanto um sistema. Alocando os métodos literal e lógico no plano sintático e os métodos histórico e teleológico tanto no plano semântico quanto no pragmático, Paulo de Barros Carvalho observa que "O critério sistemático da interpretação envolve os três planos e é, por isso mesmo, exaustivo da linguagem do direito. Isoladamente, só o último (sistemático) tem condições de prevalecer, exatamente porque ante-supõe os anteriores. É, assim, considerado o método por excelência". CARVALHO, Paulo de Barros. Curso de direito tributário. 19. ed., São Paulo: Saraiva, 2007, p.102.

${ }^{8}$ Fredie Didier Júnior, citando Sérgio Nojiri, explica que a função endoprocessual é aquela "[...] segundo a qual a fundamentação permite que as partes, conhecendo as razões que formaram o convencimento do magistrado, possam saber se foi feita uma análise apurada da causa, a fim de controlar a decisão por meio dos recursos cabíveis, bem como para que os juízes de hierarquia superior tenham subsídios para reformar ou manter essa decisão" NOJIRI, Sérgio apud DIDIER JÚNIOR, Fredie. Sobre a fundamentação da decisão judicial. Coletânea em comemoração aos quinze anos do Curso de Especialização em Direito Processual Civil do Centro de Extensão Universitária (CEU)São Paulo: Centro de Extensão Universitária, 2012, p.5. Disponível em: http://www.frediedidier.com.br/wp-content/uploads/2012/02/sobre-a-fundamentacao-da-decisao-judicial.pdf. Acesso em 03 ago 2017.

9 Fredie Didier Júnior explica que a função exoprocessual ou extraprocessual, é aquela "[...] pela qual a fundamentação viabiliza o controle da decisão do magistrado pela via difusa da democracia participativa, exercida pelo povo em cujo nome a sentença é pronunciada. Não se pode esquecer que o magistrado exerce parcela de poder que lhe é atribuído (o poder jurisdicional), mas que pertence, por força do parágrafo único do Art. 10 da Constituição Federal, ao povo". DIDIER JÚNIOR, Fredie. Sobre a fundamentação da decisão judicial. Coletânea em comemoração aos quinze anos do Curso de Especialização em Direito Processual Civil do Centro de Extensão Universitária (CEU)São Paulo: Centro de Extensão Universitária, 2012, p.5. Disponível em: http://www.frediedidier.com.br/wp-content/uploads/2012/02/sobre-a-fundamentacao-da-decisao-judicial.pdf. Acesso em 03 ago 2017.

${ }^{10}$ Normas jurídicas ou normas jurídicas em sentido estrito consubstanciam-se no juízo condicional construído, de maneira lógica, a partir da análise associativa de duas ou mais proposições da linguagem prescritiva contida no sistema de direito positivado. Elas constituem a realidade jurídica e têm por finalidade disciplinar comportamentos humanos. Paulo de Barros Carvalho divide as
} 
alternativo para a resolução do conflito seja a mediação. Por outro lado, se não há este vínculo entre as partes, o meio alternativo para a resolução do conflito será a conciliação.

A conciliação, a mediação e outros meios alternativos de solução consensual de conflitos, são institutos que devem contar com o incentivo por parte dos magistrados, dos advogados, dos defensores públicos e dos membros do Ministério Público, vez que o Art. $3^{\circ}, \mathbb{\$} 3^{\circ}$, do NCPC, as prevê como normas fundamentais do processo civil, ou seja, tais institutos são imprescindíveis e devem ser invocados no curso do processo judicial pelos representantes acima mencionados.

\section{O PAPEL DOS AUXILIARES DA JUSTIÇA DIANTE DO PODER/DEVER DO MAGISTRADO EM PROMOVER A AUTOCOMPOSIÇÃO}

O Art. 139, do NCPC, trata dos poderes jurisdicionais, os quais se subdividem em poderes-meio e poderes-fim.

São poderes-meio os ordinatórios, nos quais o juiz dá andamento ao processo, e os instrutórios, que se referem à formação do convencimento judicial.

Com relação aos poderes-fim, estes se dividem em decisórios e executórios. Os decisórios dão ao juiz o poder de resolver as questões que lhe são submetidas, e os executórios permitem ao juiz a atuação prática do comando contido na decisão.

No entanto, todos os poderes do juiz são, em verdade, poderes-deveres (CÂMARA, 2014, p.174-175), já que a um só tempo "[...] o legislador processual põe nas mãos do juiz poderes para bem dirigir o processo e deveres de observar o conteúdo das normas respectivas" (THEODORO JÚNIOR, 2014, p.246).

Dentre os poderes/deveres do magistrado está a incumbência de promover, a qualquer tempo, a autocomposição, preferencialmente com o auxílio de conciliadores e mediadores judiciais, conforme o preconizado no Art. 139, inciso V, do NCPC (BRASIL, 2015).

A autocomposição, como o próprio nome já induz, decorre da resolução trazida ao conflito pelas próprias partes, através do auxílio de terceiro imparcial, mediador ou conciliador.

A interpretação comparativa do Art. 125, inciso IV, da Lei n. 5.869/73 - antigo CPC, com o Art. 139, inciso $\mathrm{V}$ do NCPC, denota uma evolução legislativa no que se refere à autocomposição, pois a lei anterior previa a

normas jurídicas em duas espécies, as normas jurídicas em sentido amplo e as normas jurídicas em sentido estrito, e realiza uma distinção de acordo com o seu emprego: "[...] "normas jurídicas em sentido amplo" para aludir aos conteúdos significativos das frases do direito posto, vale dizer, aos enunciados prescritivos, não enquanto manifestações empíricas do ordenamento, mas como significações que seriam construídas pelo intérprete. Ao mesmo tempo, a composição articulada dessas significações, de tal sorte 
incumbência de o magistrado promover tão somente a conciliação, enquanto o NCPC prevê a incumbência do magistrado promover qualquer tipo de autocomposição, de preferência, com o auxílio de conciliadores e mediadores.

A preferência pelo auxílio de conciliadores e mediadores, prevista no NCPC, visa resolver um problema de comunicação, muitas vezes, estabelecido entre os magistrados e os jurisdicionados, pois, no mais das vezes, os magistrados, durante as audiências de mediação, de conciliação ou de instrução e julgamento, utilizam-se, exacerbadamente da linguagem ${ }^{11}$ do Direito, quando na verdade deveriam utilizar-se da linguagem social do local onde estão prestando a atividade jurisdicional.

Desta forma, a determinação disposta no Art. 139, inciso V, do NCPC, de que a autocomposição seja realizada, de preferência, com o auxílio de conciliadores e mediadores, revela-se de suma importância para a resolução de eventuais problemas de comunicação atinentes ao uso exacerbado da linguagem do Direito.

Para tanto, nos termos do Art. 167, $\$ 1^{\circ}$ do NCPC, os conciliadores e mediadores, para exercerem o seu papel, na condição de auxiliares da justiça, deverão realizar curso ministrado por entidade credenciada, conforme parâmetro curricular definido pelo Conselho Nacional de Justiça em conjunto com o Ministério da Justiça.

O mediador não possui poder decisório, ele deve manter-se neutro e agir com imparcialidade durante a mediação, de forma a conduzir as partes a uma resolução aceitável do conflito, sem emitir pareceres, sugestões ou orientações (RODRIGUES JÚNIOR, 2006, p.75), cuidando apenas “[...] do relacionamento e da descoberta dos verdadeiros interesses reais de cada uma das partes" (SILVA, 2004, p.109).

De igual forma, o conciliador não possui poder de decisão, no entanto, diferentemente do mediador, ele influência na decisão, pois, pode orientar e dar sugestões às partes, visando à obtenção do acordo. A tal respeito, Walsir Edson Rodrigues Junior exemplifica que:

[...] diante de um conflito a respeito do valor de uma indenização, o conciliador pode sugerir o meio termo entre o que é ofertado por uma das partes e o que é pedido pela outra, ou sugerir o parcelamento desse valor, ou persuadir, alertando sobre qual deverá ser a solução do juiz para o caso. (RODRIGUES JÚNIOR, 2006, p.75)

Importante salientar que, conforme previsto no Art. 166, do NCPC, ambos auxiliares da justiça, no

que produza mensagens com sentido deôntico-jurídico completo, receberia o nome de "normas jurídicas em sentido estrito"”. CARVALHO, Paulo de Barros. Direito Tributário, Linguagem e Método. 3 ed. São Paulo: Noeses, 2009, p.128.

${ }^{11}$ Língua é um código que permite a comunicação, um sistema de signos e combinações. Ela tem caráter abstrato e dispõe de um sistema de sons, sendo, a fala, sua concretização. Ela varia de acordo com a comunidade e o local. Linguagem é o sistema de signos mais complexo, o qual é utilizado para satisfazer uma necessidade de inserção do ser humano na sociedade, qual seja estabelecer uma comunicação. Neste sentido, Jonathan Barros Vita afirma que "linguagem é repertório, forma de expressão, espécie, é um conjunto sistematizado de signos funcionando como meio de comunicação de ideias” VITA, Jonathan Barros. Valoração aduaneira e preços de transferência: pontos de conexão e distinções sistêmico-aplicativas. 2010, 927f, p.30. Tese de Doutorado - Pontifícia Universidade Católica. São Paulo. Disponível em: https://sapientia.pucsp.br/bitstream/handle/5458/1/Jonathan\%20Barros\%20Vita.pdf. Acesso em: 06 abr 2017.. Qualquer tipo 
desempenho da atividade de conciliador ou de mediador, deverão balizar-se pelos mesmos princípios, quais sejam os "[...] princípios da independência, da imparcialidade, da autonomia da vontade, da confidencialidade, da oralidade, da informalidade e da decisão informada" (BRASIL, 2015), além dos princípios da competência, do respeito à ordem pública e às leis vigentes, do empoderamento e da validação, previstos, juntamente com os anteriores, no Art. 1º, do Anexo III (Código de Ética de Conciliadores e Mediadores Judiciais), da Resolução nº 125/10 do CNJ, o qual também consigna as definições conotativas de cada um destes princípios. ${ }^{12}$

No entanto, nem o Art. 166, do NCPC, nem o Art. 1ª, do Anexo III, da Resolução no 125/10 do CNJ, consignaram as definições dos princípios da oralidade e da informalidade.

Conotativamente o princípio da oralidade pode ser definido como a possibilidade das partes envolvidas no conflito, e também do terceiro imparcial, manifestarem-se o quanto for possível de maneira verbal no processo, inobstante, a possibilidade de manifestarem-se de forma escrita e de reduzirem a termo o acordo firmado.

Também de forma conotativa, o princípio da informalidade pode ser definido como a possibilidade de as partes terem "[...] ampla liberdade para estabelecer as regras e a mecânica do processo [...]. Elas podem formular o cronograma a ser seguido, o local e o tipo de reuniões. Tudo isso dependerá da natureza do conflito e das características das partes [...]" (RODRIGUES JÚNIOR, 2006, p.88).

Relevante explicitar que o princípio da informalidade encontra-se, de forma esparsa, previsto em diversos enunciados prescritivos ${ }^{13}$ do NCPC, por exemplo, quando, no Art. 166 , $\$ 4^{\circ}$, permite aos interessados definir as regras procedimentais a serem seguidas; quando, no Art. 168, atribui às partes a faculdade de escolherem, de comum acordo, o terceiro imparcial; quando, no Art. 190, permite às partes estipular mudanças no procedimento para ajustá-lo às especificidades da causa; e quando, no Art. 696, possibilita, nas ações de família, a divisão das sessões de mediação e conciliação em tantas quantas sejam necessárias para viabilizar a solução consensual (BRASIL, 2015).

Nos termos do Art. 167, do NCPC (BRASIL, 2015), os advogados podem credenciar-se como mediadores ou conciliadores, no entanto, conforme interpretação sistemática do contido no $\$ 5^{\circ}$, do mesmo artigo, como o contido no Art. 28, inciso II, da Lei no 8.906/1994 (BRASIL, 1994), e no Art. 8ª, caput e $\$ 1^{\circ}$ do

de linguagem surge e se desenvolve pautada no uso de um sistema de comunicação, ou seja, todo tipo de linguagem surge e se desenvolve pautada no uso da língua.

${ }^{12}$ Ver Art. 1', do Anexo III, da Resolução no 125/10 do CNJ.

${ }^{13}$ Paulo de Barros Carvalho afirma que os enunciados prescritivos são os "conteúdos significativos das frases do direito posto". CARVALHO, Paulo de Barros. Direito Tributário, Linguagem e Método. 3 ed. São Paulo: Noeses, 2009, p.128. Citando Riccardo Guastini, reforça o autor afirmando que "uma coisa são os enunciados prescritivos, isto é, usados na função pragmática de prescrever condutas; outra, as normas jurídicas, como significaçōes construídas a partir dos textos positivados e estruturadas consoante a forma lógica dos juízos condicionais, compostos pela associação de duas ou mais proposiçōes prescritivas. É exatamente o que ensina Ricardo Guastini, de modo peremptório: "um documento normativo (uma fonte del diritto) è um 
Regulamento Geral do Estatuto da Ordem dos Advogados do Brasil (CONSELHO FEDERAL DA ORDEM DOS ADVOGADOS DO BRASIL, 1994), aqueles advogados que se credenciarem ficarão impedidos de exercer a advocacia nos juízos em que exercerem suas funções.

Neste ponto, relevante abordar que, ainda que o advogado descredencie-se do cadastro de mediadores ou conciliadores, despindo-se da investidura de conciliador ou mediador, ficará impedido, pelo prazo de um ano, a contar da data da última audiência em que atuou, de prestar quaisquer serviços advocatícios às partes que participaram de audiência de mediação ou conciliação presidida por ele. Assim, nestes casos, o advogado não poderá postular a órgão do Poder Judiciário e nem realizar atividades de consultoria, assessoria e direção jurídicas, conforme prevê o Art. 172 do NCPC (BRASIL, 2015).

Nos casos em que haja motivos ensejadores de impedimento ou suspeição, deverá o mediador ou o conciliador comunicar seu impedimento ou suspeição ao juiz da causa ou ao coordenador do centro judiciário de solução de conflitos e cidadania, a fim de que haja nova distribuição, conforme se pode depreender da interpretação sistemática do contido nos Arts. 144, 145 e 170 (BRASIL, 2015), do NCPC, com o contido no Art. 5o, do Anexo III (Código de Ética de Conciliadores e Mediadores Judiciais) da Resolução no 125/10 do CNJ (BRASIL, 2010).

Caso o mediador ou o conciliador não observe tal regramento, ou qualquer outro regramento ou princípio que informe a mediação e a conciliação, poderá ser submetido a processo administrativo, o qual poderá culminar em sua exclusão do cadastro nacional e do cadastro de Tribunal de Justiça ou de Tribunal Regional Federal, conforme prevê o Art. 173 do NCPC (BRASIL, 2015).

O NCPC trouxe outra inovação no que se refere à mediação e à conciliação, pois o termo de acordo elaborado pelo mediador ou pelo conciliador, que outrora, no CPC anterior - Lei no 5.869/73, necessitava da homologação da autoridade judiciária, já não necessita mais de tal homologação, vez que foi inserido no rol dos títulos executivos extrajudiciais do Art. 784, inciso IV, do NCPC (BRASIL, 2015), fato que proporciona maior celeridade de execução a tal acordo.

No entanto, a contrario sensu, o enunciado prescritivo contido no Art. 334, \$1 1, do NCPC descreve que a autocomposição obtida será reduzida a termo e homologada por sentença (BRASIL, 2015).

Diante disso surge a dúvida referente à necessidade de o acordo firmado pelo conciliador ou pelo mediador ser homologado ou não pela autoridade judiciária para ter valia como título executivo.

Assim, cumpre salientar que a autocomposição realizada pelo mediador ou pelo conciliador tem natureza de título executivo, sendo importante explicitar que, caso não seja homologada pela autoridade judiciária,

aggregato di enunciati del discorso prescritivo"”. (grifo do autor) CARVALHO, Paulo de Barros. Direito Tributário, Linguagem e Método. 3 ed. São Paulo: Noeses, 2009, p.129. 
terá natureza de título executivo extrajudicial, porém, caso seja homologada pela autoridade judiciária, terá natureza de título executivo judicial.

Os poderes atribuídos pelo NCPC aos mediadores e aos conciliadores poderão servir como uma forma de dar maior celeridade de conclusão aos casos apresentados aos Centros Judiciários de Solução de Conflitos e Cidadania, doravante denominados por Cejusc's ou Centros, os quais, conforme a Resolução no 125/10 do CNJ, têm a finalidade de atender aos Juízos, Juizados ou Varas com competência nas áreas cível, fazendária, previdenciária, de família ou dos Juizados Especiais Cíveis e Fazendários, e são unidades do Poder Judiciário, preferencialmente, responsáveis por realizar, de forma extrajudicial, sessões e audiências de conciliação e mediação a cargo de conciliadores e mediadores, assim como para atendimento e orientação ao cidadão.

Esta maior celeridade poderá possibilitar uma maximização de eficiência ${ }^{14}$ na Justiça brasileira, por meio de uma resolução alternativa de conflitos, apta a garantir a fruição plena do direito de acesso à justiça, baseada na fruição tempestiva, pelos cidadãos, dos direitos que lhe foram tolhidos ou negados ilegalmente, garantindo-lhes viver uma vida digna e contribuindo, assim, para a efetivação do princípio fundamental da dignidade da pessoa humana e para a construção de uma sociedade justa e solidária, princípio e objetivo fundamentais da República Federativa do Brasil, respectivamente, previstos no Art. 1º inciso III, e no Art. $3^{\circ}$, inciso I, da Constituição Federal de 1988 (BRASIL, 1988).

\section{A MEDIAÇÃO E A CONCILIAÇÃO NOS PROCEDIMENTOS COMUM E ESPECIAL}

A mediação, assim como a conciliação, foi acrescida no NCPC também como forma endoprocessual de resolução de conflito no procedimento comum e nas ações de família, que seguem procedimento especial. Pretendeu-se, com isso:

[...] converter o processo em instrumento incluído no 'contexto social' em que produzirá efeito o seu resultado. Deu-se ênfase à possibilidade de as partes porem fim ao conflito pela via da mediação ou da conciliação. Entendeu-se que a 'satisfação efetiva' das partes pode se dar de modo mais intenso se a solução é por elas criada e não imposta pelo juiz (MARINONI e MITIDIERO, 2010, p.215).

Diante da mediação e da conciliação as decisões certamente corresponderão "[...] à necessidade das partes e ao empenho social na prevenção e composição deles [dos conflitos] [...]” (BERMUDES, 2006, p.17-18),

\footnotetext{
${ }^{14} \mathrm{O}$ termo eficiência possui diversas concepções, como a eficiência de Pareto [...] e a eficiência de Kaldor-Hicks COOTER, Robert; ULEN, Thomas. Law and Economics. Addison Wesley. 6. ed. Berkeley Law Books, 2016, p.14, 42-43. No entanto, por motivo de corte metodológico, neste artigo adota-se a concepção de que a eficiência relaciona-se à maximização de ganhos e à minimização de custos. Assim, há maximização da eficiência se houver possibilidade de aumentar os benefícios - externalidades positivas - sem aumentar os custos - externalidade negativas. .
} 
de forma a revelar, além da resolução tempestiva dos conflitos, outra característica de maximização de eficiência na Justiça Brasileira, qual seja a qualidade das sentenças judiciais, pois, traduzirão a vontade efetiva das partes.

Na sequência, analisar-se-ão em quais momentos, nos procedimentos comum e especial, a mediação e a conciliação deverão ser invocadas.

\section{Requisitos da petição inicial}

Diferentemente do CPC anterior, o NCPC, no Art. 319, inciso VII, inseriu mais um requisito obrigatório da petição inicial, dentre os já existentes, qual seja a indicação pelo autor se opta pela realização ou não de audiência de conciliação ou de mediação (BRASIL, 2015).

Assim, por tratar-se de requisito obrigatório da petição inicial, caso o autor não o observe, a autoridade judiciária determinará que a petição inicial seja emendada ou completada, devendo o autor, no prazo de quinze dias, indicar se opta ou não pela realização de audiência de conciliação ou de mediação, sob pena de indeferimento da inicial, nos termos do Art. 321, do NCPC (BRASIL, 2015).

Nos termos do Art. 334, $\$ 4^{\circ}$, incisos I e II, do NCPC, a supressão do ato processual de mediação ou conciliação, com o prosseguimento da demanda, ocorrerá, respectivamente, "se ambas as partes manifestarem, expressamente, desinteresse na composição consensual", ou "quando não se admitir a autocomposição" (BRASIL, 2015).

\section{A audiência de conciliação ou de mediação no procedimento comum}

O magistrado, ao constatar que a petição inicial atende aos requisitos legais e que as partes possuem interesse na composição consensual, designará, conforme o objeto do litígio, a audiência de conciliação ou de mediação.

Traz inquietude o contido no Art. 334, $\$ 5^{\circ}$, última parte, do NCPC, que oportuniza ao réu peticionar, informando seu desinteresse na autocomposição, com um prazo de 10 dias de antecedência, contados da data da audiência (BRASIL, 2015).

Tal enunciado prescritivo pode levar à falsa percepção de que estará o réu obrigado à autocomposição, caso não se manifeste em tal prazo e o autor tenha manifestado seu interesse de autocomposição na petição inicial.

No entanto, não é esta a melhor interpretação, pois, pelos mais variados motivos, o réu pode ser citado quando tal prazo já não mais exista, por exemplo, pode o réu ser citado com 7 dias de antecedência da data da audiência. 
Neste caso, não seria razoável impedir o réu de exercer o seu direito de oposição à autocomposição. De igual forma, tendo em vista a maximização de eficiência da Justiça, por meio da celeridade processual, não seria razoável exigir-se a redesignação da audiência de mediação ou de conciliação.

Assim, a solução mais ponderada será o comparecimento do réu na data da audiência de mediação e conciliação, oportunidade em poderá manifestar seu interesse ou não pela autocomposição.

Em relação ao comparecimento à audiência, importante explicitar que o não comparecimento injustificado à audiência de mediação ou de conciliação é considerado ato atentatório à dignidade da justiça ${ }^{15}$, ficando o autor ou o réu, conforme o caso, sujeito à sanção de "[...] multa de até dois por cento da vantagem econômica pretendida ou do valor da causa, revertida em favor da União ou do Estado” (BRASIL, 2015).

Assim, caso não possa comparecer à audiência de mediação ou de conciliação o autor ou o réu deverá apresentar, nos autos, a justificativa para sua ausência. Poderá ainda, qualquer deles, constituir representante, para o qual deverá outorgar poderes específicos, via procuração, para negociar e transigir, sendo defeso ao advogado cumular as funções de advogado e de representante, em virtude do impedimento previsto no Art. 26, do Código de Ética e Disciplina da Ordem dos Advogados do Brasil, e que sua presença na audiência é indispensável (ORDEM DOS ADVOGADOS DO BRASIL, 1995).

No que se refere à presidência da audiência de mediação ou de conciliação em sede processual, cumpre salientar que nem sempre ela será presidida por um mediador ou por um conciliador, pois, ela poderá ser presidida pela autoridade judiciária, conforme prevê o Art. 139, inciso V, do NCPC (BRASIL, 2015).

No entanto, em virtude de problemas de linguagem, ocorridos durante audiências presididas por alguns Juízes, conforme abordado anteriormente, o ideal seria que as audiências de mediação ou de conciliação fossem conduzidas por mediadores ou conciliadores, que atuariam, com base na sua capacitação específica, visando à adequação da linguagem processual à linguagem social das partes do processo e, com isso, possibilitando a autocomposição de forma mais célere e efetiva, já que as partes teriam condições de entender todas as suas possibilidades para uma resolução consensual do conflito.

Nos termos do Art. 334, \$5º do NCPC, caso a audiência de mediação ou de conciliação reste infrutífera, poderá o presidente da mesma, caso tenha a percepção de que o consenso das partes possa se dar em outra oportunidade, redesignar a audiência quantas vezes forem necessárias, desde que as realize no período de dois meses, contados da primeira audiência em que restou frustrada a autocomposição (BRASIL, 2015).

Caso todas as tentativas possíveis de mediação ou conciliação tornem-se infrutíferas, dar-se-á início a

\footnotetext{
${ }^{15}$ Conforme Vilian Bollmann o ato atentatório à dignidade da justiça "[...] consiste na realização de ato contrário à ordem previamente ditada, ou seja, ofensa à regra jurídica individual estabelecida”. BOLLMANN, Vilian. O ato atentatório à dignidade da
} 
contagem do prazo de 15 dias para que o réu apresente sua contestação, nos termos do Art. 335, inciso I, do NCPC, após o qual será designada a audiência de instrução e julgamento, se necessária ${ }^{16}$ no caso sub judice.

\section{A audiência de instrução e julgamento no procedimento comum}

O Capítulo do NCPC que abarca a audiência de instrução e julgamento engloba os Arts. 358 a 368, no entanto, em razão de corte metodológico, tendo em vista o objetivo do presente artigo, será objeto de interpretação tudo aquilo que se aplicar à mediação e à conciliação.

Em que pese ter havido tentativas de mediação ou de conciliação antes desta fase processual, iniciada a audiência de instrução e julgamento o juiz tentará conciliar as partes, por meio da mediação ou da conciliação.

Neste ponto, muito embora a legislação em vigor não contemple a participação do mediador e do conciliador neste momento processual, seria muito importante à maximização de eficiência da Justiça, que a autoridade judiciária convocasse-os, para a condução da solução consensual de conflitos, em virtude dos problemas de linguagem, já abordados anteriormente, que podem ocorrer durante a audiência.

No entanto, se mesmo com a presença destes auxiliares da justiça as partes não chegarem a um consenso, o juiz dará seguimento aos demais atos processuais, visando por fim à audiência de instrução e julgamento.

\section{Procedimento especial nas ações de família}

O NCPC engloba, dentre os procedimentos especiais, as ações de família, mais especificamente, os processos contenciosos de divórcio, separação, reconhecimento e extinção de união estável, guarda, visitação e filiação.

É cediço que, anteriormente ao conflito instalado, nas ações de família as partes envolvidas sempre mantiveram um vínculo, sobretudo, afetivo. Neste contexto, o método mais apropriado à solução consensual de conflito familiar é a mediação, já que a conciliação é utilizada nos casos em que as partes não possuem um vínculo anterior ao conflito.

Assim, a melhor redação para os enunciados prescritivos dos Arts. 693 a 699, do NCPC, seria aquela que contemplasse apenas a mediação como método para a solução consensual de controvérsias no âmbito das ações de família, vez que a mediação "[...] apresenta-se como um caminho alternativo à resolução dos litígios no âmbito

jurisdição: constitucionalizando o parágrafo único do Art. 14 do CPC com base no direito à efetividade do acesso à Justiça. Revista de Doutrina da 4a Região, n. 7, 18 jul. 2005, p. 1-14, p.3.

${ }^{16}$ Ver Art. 354, 355 e 356, do NCPC. 
familiar, no qual há a preocupação fundamental com a preservação emocional das partes" (RODRIGUES JÚNIOR, 2006, p.102-103).

Afirma-se isso, pois, a mediação oferece "[...] um ambiente pacificador para que as negociações se produzam sem enfrentamentos e coloca um modelo de trabalho baseado na autodeterminação do próprio casal para que resolvam as discrepâncias mantidas e decidam a opção mais viável para todo o grupo familiar" (SILVA, 2004, p.54).

Visando à maximização de eficiência na resolução dos conflitos no âmbito das ações de família, é importante que, na audiência de mediação pré ou pós-processual, o mediador familiar demonstre o que sustenta e o que enfraquece a família, aquilo que contribui ou prejudica o seu bom funcionamento (SIX, 2001, p.67), pois, assim, por meio da conscientização das partes, poderá chegar a um consenso, pondo fim de forma célere e efetiva ao conflito. Como exemplo, pode-se citar o caso de uma dissolução da sociedade conjugal, caso em que o mediador deverá buscar:

[...] o entendimento de que o relacionamento chegou ao fim. E, quando da existência de filhos comuns, prevaleça a consciência de que o relacionamento como marido e mulher não deu certo, mas que como pai e mãe, sempre no melhor interesse dos filhos, tal relacionamento deve continuar, agora, entre pais, e não entre marido e mulher (RODRIGUES JÚNIOR, 2006, p.102).

Desta forma, fica explicita a preocupação do NCPC em fomentar a solução consensual de conflitos, seja através da mediação ou da conciliação, não só no procedimento comum, mas também no especial, mais especificamente nas ações de família.

\section{CONSIDERAÇÕES FINAIS}

A conciliação e a mediação são meios alternativos de resolução de conflitos que, atualmente, estão em evidência, em virtude de possibilitarem uma resolução mais célere dos processos judiciais e, por vezes, evitarem a sua instauração, possibilitando, com isso, o tão almejado desafogamento do Poder Judiciário.

Conotativamente, a mediação pode ser definida como o meio alternativo para resolução de conflito, através do qual o mediador incentiva as partes litigantes a colocarem fim a um litígio para que não haja a necessidade de judicialização da demanda, aproveitando-se de uma eventual relação de proximidade pré-existente entre as partes litigantes, cabendo ao mediador apenas conduzir o processo de facilitação da comunicação para a resolução consensual do litígio.

Também conotativamente, a conciliação pode ser definida como o meio alternativo para resolução de conflito, através do qual o conciliador incentiva o fim de um litígio, iniciado em uma situação casual, na qual as partes não se conheciam anteriormente, visando a não judicialização da demanda, cabendo ao mediador apenas 
conduzir o processo de facilitação da comunicação para a resolução consensual do litígio.

Portanto, se o conflito apresentado for oriundo de um vínculo anterior entre as partes, isto é, de um laço que os une de amizade, de vizinhança, de sangue, de afeto, por exemplo, a norma jurídica indica que o meio alternativo para a resolução do conflito seja a mediação. Por outro lado, se não há este vínculo entre as partes, o meio alternativo para a resolução do conflito será a conciliação.

A interpretação comparativa do Arts. 125, inciso IV, da Lei n. 5.869/73 - antigo CPC, com o Arts. 139, inciso $\mathrm{V}$ do NCPC, denota uma evolução legislativa no que se refere à autocomposição, pois a lei anterior previa a incumbência de o magistrado promover tão somente a conciliação, enquanto o NCPC prevê a incumbência do magistrado promover qualquer tipo de autocomposição, de preferência, com o auxílio de conciliadores e mediadores.

A preferência pelo auxílio de conciliadores e mediadores, prevista no NCPC, visa resolver um problema de comunicação, muitas vezes, estabelecido entre os magistrados e os jurisdicionados, pois, no mais das vezes, os magistrados, durante as audiências de mediação, de conciliação ou de instrução e julgamento, utilizam-se, exacerbadamente da linguagem do Direito, quando na verdade deveriam utilizar-se da linguagem social do local onde estão prestando a atividade jurisdicional.

Desta forma, a determinação disposta no Art. 139, inciso V, do NCPC, de que a autocomposição seja realizada, de preferência, com o auxílio de conciliadores e mediadores, revela-se de suma importância para a resolução de eventuais problemas de comunicação atinentes ao uso exacerbado da linguagem do Direito.

O NCPC trouxe outra inovação no que se refere à mediação e à conciliação, pois o termo de acordo elaborado pelo mediador ou pelo conciliador, que outrora, no CPC anterior - Lei no 5.869/73 necessitava da homologação da autoridade judiciária, já não necessita mais de tal homologação, vez que foi inserido no rol dos títulos executivos extrajudiciais do Art. 784, inciso IV, do NCPC (BRASIL, 2015), fato que proporciona maior celeridade de execução a tal acordo.

A autocomposição realizada pelo mediador ou pelo conciliador tem natureza de título executivo, sendo importante explicitar que, caso não seja homologada pela autoridade judiciária, terá natureza de título executivo extrajudicial, porém, caso seja homologada pela autoridade judiciária, terá natureza de título executivo judicial.

Os poderes atribuídos pelo NCPC aos mediadores e aos conciliadores poderão servir como uma forma de dar maior celeridade de conclusão aos casos apresentados aos Centros Judiciários de Solução de Conflitos e Cidadania, doravante denominados por Cejusc's ou Centros, os quais, conforme a Resolução no 125/10 do CNJ, têm a finalidade de atender aos Juízos, Juizados ou Varas com competência nas áreas cível, fazendária, previdenciária, de família ou dos Juizados Especiais Cíveis e Fazendários, e são unidades do Poder Judiciário, preferencialmente, responsáveis por realizar, de forma extrajudicial, sessões e audiências de conciliação e mediação 
a cargo de conciliadores e mediadores, assim como para atendimento e orientação ao cidadão.

Esta maior celeridade poderá possibilitar uma maximização de eficiência na Justiça brasileira, por meio de uma resolução alternativa de conflitos, apta a garantir a fruição plena do direito de acesso à justiça, baseada na fruição tempestiva, pelos cidadãos, dos direitos que lhe foram tolhidos ou negados ilegalmente, garantindo-lhes viver uma vida digna e contribuindo, assim, para a efetivação do princípio fundamental da dignidade da pessoa humana e para a construção de uma sociedade justa e solidária, princípio e objetivo fundamentais da República Federativa do Brasil, respectivamente, previstos no Art. 1º, III, e no Art. 3º I, da Constituição Federal de 1988 (BRASIL, 1988).

\title{
THE MEDIATION AND CONCILIATION IN THE NEW CODE OF CIVIL PROCEDURE: MAXIMIZATION OF EFFICIENCY IN THE BRAZILIAN JUSTICE
}

\begin{abstract}
This article aims to analyze the development of new methodologies and tendencies of the Civil Procedure in relation to the alternative means of conflict resolution and the bases on which they are based, from the point of view of self - composition. To that end, are investigated the definitions and the differences between these two Institutes, a possible legislative developments concerning the mediation and conciliation, the legal nature of the agreements reached within the framework of these institutes and a possible maximization of efficiency in the Brazilian Justice afforded by them. To obtain the desired results by research, the method of approach to be followed was the empirical-dialectic, using the research literature and legislation, taking as reference system for a combination of Logical-Semantic Constructivism of Paulo de Barros Carvalho and Law and Economics of Richard A. Posner. In conclusion, it is pointed to a widening of the speed of procedure, which allows a maximization of efficiency in the Brazilian Justice, by means of an alternative resolution of conflicts to ensure the full enjoyment of the right to access to justice, based on the timely fruition, by citizens, the rights that have been hijacked or denied illegally.
\end{abstract}

Keywords: Postmodernity. Alternative means of conflict resolution. Maximization of efficiency. Access to Justice. Dignity of the human person.

\section{REFERÊNCIAS BIBLIOGRÁFICAS}

BERMUDES, Sérgio. Introdução ao processo civil. $4^{a}$ ed. rev. e atual. Rio de Janeiro: Forense, 2006.

BOLLMANN, Vilian. $\mathrm{O}$ ato atentatório à dignidade da jurisdição: constitucionalizando o parágrafo único do art. 14 do CPC com base no direito à efetividade do acesso à Justiça. Revista de Doutrina da $4^{a}$ Região, n. 7, 18 jul. 2005, p. 1-14.

BRASIL. Lei no 5.869, de 11 de janeiro de 1973. Disponível em 
http://www.planalto.gov.br/ccivil_03/leis/L5869.htm. Acesso 08 ago 2017.

Lei $\mathrm{n}^{\circ}$ 8.906, de 04 de julho de 1994. Disponível em http://www.planalto.gov.br/ccivil_03/leis/L8906.htm. Acesso em 08 ago 2017.

Conselho Nacional de Justiça. Resolução no 125, de 29 de novembro de 2010. Disponível em http://www.cnj.jus.br/atos-administrativos/atos-da-presidencia/323-resolucoes/12243-resolucao-no-125-de29-de-novembro-de-2010. Acesso em: 27 de junho de 2014.

Lei $\mathrm{n}^{\circ}$ 13.105, de 16 de março de 2015. Disponível em: http://www.planalto.gov.br/ccivil_03/_ato2015-2018/2015/lei/113105.htm. Acesso em 03 ago 2017.

BUENO, Cassio Scarpinella. Curso sistematizado de direito processual civil: Teoria geral do direito processual civil. vol 1. 5. ed. São Paulo: Saraiva, 2011.

CÂMARA, Alexandre Freitas. Lições de direito processual civil. vol. 1.25. ed. São Paulo: Atlas, 2014.

CARVALHO, Aurora Tomazini de. Teoria Geral do Direito: O Constructivismo Lógico-Semântico. 2009. 623 f. Tese de Doutorado - Pontifícia Universidade Católica. São Paulo.

CARVALHO, Paulo de Barros. Curso de direito tributário. 19. ed., São Paulo: Saraiva, 2007

Direito Tributário, Linguagem e Método. 3 ed. São Paulo: Noeses, 2009.

Constructivismo lógico-semântico. Disponível em

https://enciclopediajuridica.pucsp.br/verbete/101/edicao-1/constructivismo-logico-semantico. Acesso em 14 jun. 2017.

CONSELHO FEDERAL DA ORDEM DOS ADVOGADOS DO BRASIL. Regulamento Geral do Estatuto da Advocacia e da Ordem dos Advogados do Brasil. Disponível em http://www.oab.org.br/content/pdf/legislacaooab/regulamentogeral.pdf. Acesso em 08 ago 2017.

COOTER, Robert; ULEN, Thomas. Law and Economics. Addison Wesley. 6. ed. Berkeley Law Books, 2016.

DIDIERJÚNIOR, Fredie. Sobre a fundamentação da decisão judicial. Coletânea em comemoração aos quinze anos do Curso de Especialização em Direito Processual Civil do Centro de Extensão Universitária (CEU) São Paulo: Centro de Extensão Universitária, 2012. Disponível em: http://www.frediedidier.com.br/wp-content/uploads/2012/02/sobre-a-fundamentacao-da-decisao-judicial.pdf. Acesso em 03 ago 2017.

DIDIER JÚNIOR, Fredie. Curso de direito processual civil: Introdução ao direito processual civil e processo de conhecimento. vol. 1. 15. ed. rev. e atual. e ampl. Salvador: Jus Podivm, 2013.

DINAMARCO, Cândido Rangel. Teoria geral o processo. 23. ed. rev. e atual. São Paulo: Malheiros, 2007.

GRINOVER, Ada Pellegrini; WATANABE, Kazuo; LAGRASTA NETO, Caetano (Coords.). Mediação e gerenciamento do processo: revolução na prestação jurisdicional: guia prático para a instalação do setor de conciliação e mediação. São Paulo: Atlas, 2008.

MARINONI, Luiz Guilherme; MITIDIERO, Daniel. O projeto do CPC: crítica e propostas. São Paulo: Revista dos Tribunais, 2010. 
ORDEM DOS ADVOGADOS DO BRASIL. Código de ética e disciplina. Disponível em http://www.oab.org.br/visualizador/19/codigo-de-etica-e-disciplina. Acesso em 08 ago 2017.

POSNER, Richard A. Values and consequences: As an introduction to economic analysis of law. University of Chicago Law School. John M. Olin law \& Economics Working Paper n. 53. 2D Series. Chicago: 1998. Disponível em http://m.law.uchicago.edu/files/files/53.Posner.Values_0.pdf.Acesso em 29 jul. 2017.

RODRIGUES JÚNIOR, Walsir Edson. A prática da mediação e o acesso à justiça. Belo Horizonte: Del Rey, 2006.

SANTOS, Ricardo Soares Stersi dos. Noções gerais da arbitragem. Florianópolis: Fundação Boiteux, 2004.

SILVA, João Roberto da. A mediação e o processo de mediação. São Paulo: Paulistanajur Ltda, 2004.

SIX, Jean François. Dinâmica da mediação. Tradução de Giselle Groeninga de Almeida, Águida Arruda Barbosa e Eliana Riberti Nazareth. Belo Horizonte: Del Rey, 2001.

THEODORO JÚNIOR, Humberto. Curso de direito processual civil - Teoria geral do direito processual civil e processo de conhecimento. vol.1. 55. ed. Rio de Janeiro: Forense, 2014.

VASCONCELOS, Carlos Eduardo de. Mediação de conflitos e práticas restaurativas. São Paulo: Método, 2008.

VILANOVA, Lourival. Fundamentos do Estado de Direito. In: Escritos Jurídicos e Filosóficos, vol. I. São Paulo: IBET/Axis-Mundi, 2008.

VITA, Jonathan Barros. Valoração aduaneira e preços de transferência: pontos de conexão e distinções sistêmico-aplicativas. 2010.927f. Tese de Doutorado - Pontifícia Universidade Católica. São Paulo.

Trabalho enviado em 05 de outubro de 2017.

Aceito em 18 de janeiro de 2018. 